\title{
Effect of Ni Addition and T6 Heat Treatment on Microstructure and Microhardness of Hot Plastic Deformed (Al-Si-Mg) Alloys
}

H. M. Medrano-Prieto ${ }^{1 *}$, C.G. Garay-Reyes ${ }^{2}$, I. Estrada-Guel ${ }^{2}$, J.M. Mendoza-Daurte ${ }^{2}$, J.C Guía-Tello ${ }^{2}$, J.S. Castro-Carmona ${ }^{1}$, H. Camacho-Montes ${ }^{1}$, M. C. Maldonado-Orozco ${ }^{3}$ and R. Martínez-Sánchez ${ }^{2}$

${ }^{1}$ Universidad Autónoma de Ciudad Juárez (UACJ), Av. Plutarco Elías Calles No. 1210 Fovissste Chamizal, CP 32310, Ciudad Juárez, Chih., México,

${ }^{2}$ Centro de Investigación en Materiales Avanzados (CIMAV), Laboratorio Nacional de Nanotecnología, Miguel de Cervantes No. 120, CP 31136, Chihuahua, Chih., México.

${ }^{3}$ Universidad Autónoma de Chihuahua (UACH), Facultad de Ingeniería, Circuito No. 1, Nuevo Campus Universitario, CP 31125 Chihuahua, Chih., México.

*Corresponding author: hansel.medrano@cimav.edu.mx, c6473@uacj.mx

A356 (Al-Si-Mg) alloy have been widely used in the automotive, aerospace and military industries due to their high castability, corrosion resistance and excellent strength/weight ratio. The most important alloying elements are $\mathrm{Si}$ and $\mathrm{Mg}$. The microstructure of A356 alloy in as-cast condition is composed mainly by $\mathrm{Al}-\alpha$ dendrites, interdendritic $\mathrm{Al}-\mathrm{Si}, \mathrm{Mg}_{2} \mathrm{Si}$ phase and Fe-based intermetallics. The main applications are in the automotive, aerospace and military industries. Excellent mechanical properties of A356 alloy are obtained after T6 heat treatment, because to precipitation of $\beta^{\prime \prime}-\mathrm{Mg}_{2} \mathrm{Si}$ and $\beta^{\prime}-\mathrm{Mg}_{2} \mathrm{Si}$ coherent and semi-coherent metastable phases. In recent years previous researches have reported that an excellent combination of strength and ductility can be achieved by adding alloy elements, as well as, performing heat treatments and deformation processes. An example of such elements to reinforce Al Alloys are transition elements $(\mathrm{Ni}, \mathrm{Fe}, \mathrm{Zr}$, Ti and $\mathrm{V})$, these elements have been used due its low solubility in $\mathrm{Al}(0.01 \%$ to $0.03 \%)$ and high ability to form intermetallic compounds. It has been reported that additions of 1 to $2 \mathrm{Ni}$ (wt. \%) to Al alloys of the series $3 \mathrm{xxx}$ and $2 \mathrm{xxx}$ increase the hardness and tensile/wear properties because of to the formation of Al-Ni and Al-Ni-Cu intermetallic compounds, allowing that these alloys can be used in applications at relative high temperatures [1-5]. Thus, this investigation is focused to the variations on microstructure and hardness generated by $\mathrm{Ni}$ additions, hot plastic deformation and T6 heat treatments in A356 alloy.

A356 alloy and those modified with $\mathrm{Ni}\left(1-2\right.$ wt. \%) were hot plastic deformed at $350{ }^{\circ} \mathrm{C}$ with $50 \%$ deformation ratio, solution heat treated (SHT) at $535^{\circ} \mathrm{C}$ for $7 \mathrm{~h}$, quenching in water at $60{ }^{\circ} \mathrm{C}$ and aged at $180{ }^{\circ} \mathrm{C}$ for different period of time. Changes in the microstructure and hardness were characterized and evaluated by TEM HITACHI 7700 (operated at $120 \mathrm{kV}$ ) and Jeol JEM2200F+CS (operated at $200 \mathrm{kV}$ ) and Vickers microhardness was evaluated in LECO LM300 AT tester.

The Fig. 1 shows the behavior of the microhardness values respect to $\mathrm{Ni}$ content, hot-plasticdeformation (D) or non-deformation (ND) and aging time in A356 alloy. There are observed increments of hardness values as a function of Ni concentration. The hardness peaks are observed at $180 \mathrm{~min}(3 \mathrm{~h})$ for (ND) and $600 \mathrm{~min}(10 \mathrm{~h})$ for (D) alloys both with $2 \mathrm{Ni}$ (wt. \%). The graph illustrates similar behavior for both (D) and (ND) with 1-2 Ni (wt. \%) alloys, the hardness values remain stable since $3 \mathrm{~h}$ to $10 \mathrm{~h}$. The Ni additions and hot plastic deformation in A356 alloy favors the increments in HV values. Additionally, in samples alloyed with $\mathrm{Ni}$ the $\mathrm{HV}$ values decreases slowly during over-aging stage. Furthermore, the $\mathrm{Ni}$ addition 1-2 $\mathrm{Ni}$ (wt. \%) to the A356 alloy have an important effect on the 
microstructure; mainly in the morphology, size, distribution and number density of $\beta$ - $\mathrm{Mg}_{2} \mathrm{Si}$ precipitates formed during aging heat treatment (Fig. 2).

References:

[1] Q.G. Wang, Met. Mater. Trans. A. 34 (2003) 2887.

[2] M. A. Moustafa, F. H. Samuel, H. W. Doty, J. Mater. Sci. 38 (22) (2003) p. 4523-4534.

[3] S.K. Shaha et al, J. Alloys Compd. 615 (2014) 1019.

[4] M. T. Hayajneh, A. M. Hassan, Y. M. Jaradat, Academia.edu. 141 (2007) p. 1-5.

[5] A. Dodangeh, M.Kazeminezhadn, and H.Aashuri, Mater. Sci. Eng. A. 558 (2012) 371.

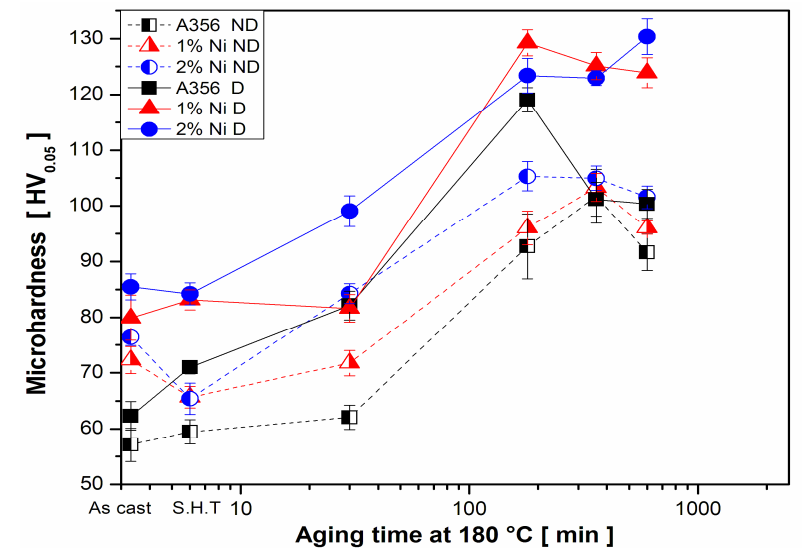

Figure 1. Evolution in hardness values respect to Ni content, hot-plastic-deformation (D) or hot-plasticnon-deformation (ND), and aging time after $7 \mathrm{~h}$ of solution treatment.

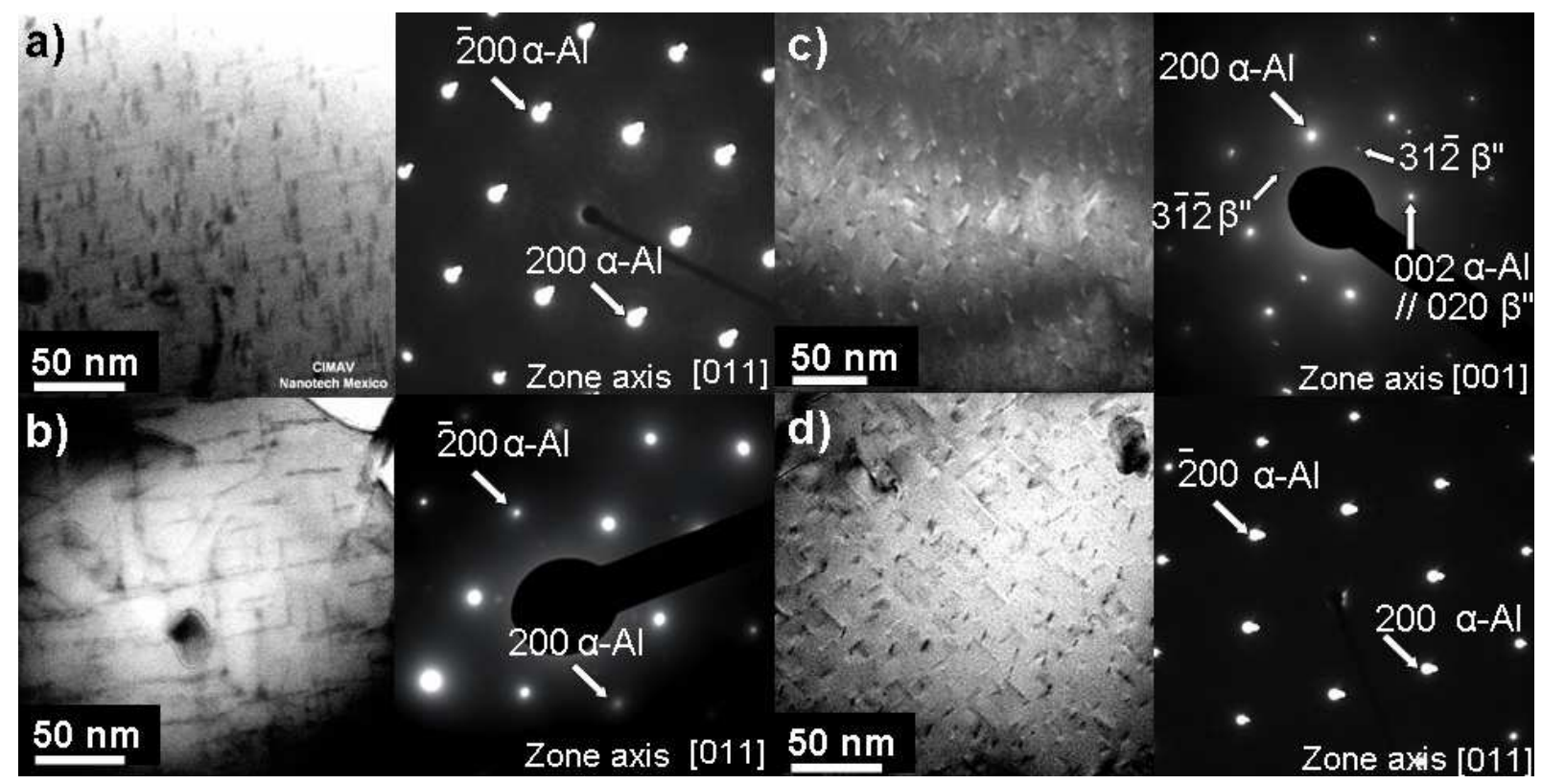

Figure 2. TEM Micrographs and SAD patterns of deformed and T6 heat treated alloys. a) and b) Bright field (BF) micrographs of reference alloy aged for 3 and $10 \mathrm{~h}$ respectively, c) and d) dark field (DF) and (BF) micrographs of A356 alloys alloyed with Ni aged for 3 and $10 \mathrm{~h}$ respectively. 